\title{
Decentralized Net-Zero Greywater Reuse for Blue Infrastructure of a Regenerative House
}

\author{
Mohammad Ramezanianpour \\ Department of Engineering and \\ Architectural Studies \\ Ara Institute of Canterbury \\ Christchurch, New Zealand
}

\author{
Muttucumaru Sivakumar \\ Faculty of Engineering and Information \\ Sciences \\ University of Wollongong \\ Wollongong, NSW, Australia
}

\begin{abstract}
The close relation between energy and water anticipates exigent situations in both aspects. Future energy and water crises must be solved in an environmental friendly and cost effective manner. Onsite greywater treatment unit is a possible sourceassociated solution that conserves the vital energy and water sources along with the enhancement of the green buildings. The main objective of this research is to treat greywater by means of a sustainable system and to produce high quality permeate water that can be re-used for multiple purposes. This research firstly compared three solar-based treatment systems from a selection of a broad range of technologies used for greywater treatment. The treatment systems were assessed through a multi-criteria decision analysis (MCDA) method embedding twelve sustainability indicators under three major criteria. Vacuum membrane distillation (VMD) was noticed as an emerging technology for water treatment. It comprises of evaporation and condensation processes that mimics the water cycle in the nature. Secondly, solar powered vacuum membrane distillation (SVMD) unit was designed, assembled and tested. This thermally-driven separation process, only allow vapor to pass through a hydrophobic porous membrane. The VMD process is rarely used for wastewater treatment due to penetration of feed through the membrane. This is called pore wetting which is yielded by active surfactants present in detergents. To overcome the problem of pore wetting, electro-coagulation (EC) was incorporated as a pretreatment unit. Finally, the EC unit assisted the SVMD system to perform a successful field test under real weather condition.
\end{abstract}

\section{Introduction}

Moving towards green building solution is not only the building design and materials, it can be a sustainable design integrated with regeneration of energy and water reuse. The aim of a regenerative house is to reduce the impact of our footprint on our environment. Net-zero impact on environment is achievable in mimicry of natural processes within energy, water and waste cycle. Renewable energy sources, water reuse and solid waste recycling support integrated resource recovery. The combination of energy, water and waste infrastructures results in reduction of greenhouse gas emissions, reduced requirements for new energy sources, reduction of potable water consumption for non-potable purposes and reduction of operational carbon footprint.

Fresh water demand increase due to the population growth, climate change and new industrial activities necessitates the importance of water recycling and preservation of water resources. In other words, remedy of the water shortage can be solved by replacement of treated water for multi-purpose usage. The main options for recycled water are industrial, agricultural, indoor and outdoor urban reuse. The challenges in conventional methods of treating and transporting potable water and wastewater creates opportunities for residential water reuse. Non-potable purposes constitutes a large portion of the residential water demand. Replacing the current infrastructure by decentralized treatment systems is a sustainable alternative. Heavily-polluted sewage such as black water is not suitable for reuse without suitable treatment [1] whereas, greywater is now accepted as a supplementary water supply option due to its quantity (70\% of the domestic wastewater) and quality (contains about $30 \%$ of the organic matters) [2]. Greywater is defined as the residential and commercial wastewater that includes water from bathtubs, spas, showers, hand basins, washing machines, laundry troughs, dishwashers and kitchen sinks excluding any input from toilets, bidets, urinals or heavily polluted industrial processed water.

Greywater reuse for a specific purpose requires the study of water-quality based effluent standards, and the effluent must satisfy acceptable guideline values. The maximum acceptable values of water-quality parameters, especially for discharge to the environment or reuse purposes, vary from country to country. Domestic water reuse standards have been developed by various countries depending on their needs. Wastewater reuse guidelines for subsurface irrigation, surface irrigation, toilet flushing and 
garden watering are provided for different sates/countries in Table 1. The turbidity, total suspended solids (TSS), biochemical oxygen demand $\left(\mathrm{BOD}_{5}\right)$ and faecal coliform counts of treated water less than $2 \mathrm{NTU}, 3 \mathrm{mg} / \mathrm{L}, 6 \mathrm{mg} / \mathrm{L}$ and $2 \mathrm{cfu} / 100 \mathrm{~mL}$, respectively are selected in this research for evaluation of the treatment technologies.

Table 1. Domestic wastewater reuse guidelines [3]

\begin{tabular}{|c|c|c|c|c|c|c|}
\hline Country & Purpose & 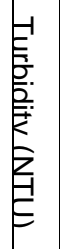 & $\begin{array}{l}\overrightarrow{1} \\
\text { 心 } \\
\widehat{3} \\
\stackrel{0}{0} \\
\stackrel{C}{C}\end{array}$ & 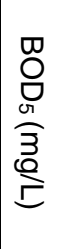 & 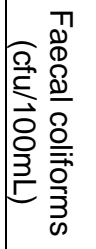 & 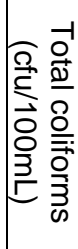 \\
\hline \multirow{3}{*}{$\begin{array}{c}\text { NSW, } \\
\text { Australi } \\
\text { a }\end{array}$} & $\begin{array}{l}\text { Subsurface } \\
\text { irrigation }\end{array}$ & - & $\begin{array}{l}4 \\
5\end{array}$ & $\begin{array}{l}3 \\
0\end{array}$ & - & - \\
\hline & $\begin{array}{l}\text { Surface } \\
\text { irrigation }\end{array}$ & - & $\begin{array}{l}4 \\
5 \\
\end{array}$ & $\begin{array}{l}3 \\
0 \\
\end{array}$ & - & 100 \\
\hline & $\begin{array}{c}\text { Toilet } \\
\text { flushing }\end{array}$ & 2 & $\begin{array}{l}2 \\
0\end{array}$ & $\begin{array}{l}2 \\
0\end{array}$ & - & 30 \\
\hline $\begin{array}{c}\text { QLD, } \\
\text { Australi }\end{array}$ & $\begin{array}{c}\text { Garden } \\
\text { watering }\end{array}$ & - & $\begin{array}{l}3 \\
0\end{array}$ & $\begin{array}{l}2 \\
0\end{array}$ & - & 100 \\
\hline $\begin{array}{c}\text { BC, } \\
\text { Canada }\end{array}$ & $\begin{array}{l}\text { Unrestricted } \\
\text { non-potable }\end{array}$ & 2 & 5 & $\begin{array}{l}1 \\
0 \\
\end{array}$ & 2.2 & - \\
\hline \multirow{2}{*}{ China } & $\begin{array}{c}\text { Toilet } \\
\text { flushing }\end{array}$ & 5 & - & $\begin{array}{l}1 \\
0\end{array}$ & 3 & - \\
\hline & $\begin{array}{l}\text { Washing } \\
\text { purpose }\end{array}$ & 5 & - & 6 & 3 & - \\
\hline $\begin{array}{c}\text { German } \\
y\end{array}$ & $\begin{array}{l}\text { Unrestricted } \\
\text { non-potable }\end{array}$ & 2 & - & $\begin{array}{l}2 \\
0 \\
\end{array}$ & 100 & 500 \\
\hline Japan & Landscape & 5 & - & 1 & 10 & 10 \\
\hline Spain & $\begin{array}{l}\text { Unrestricted } \\
\text { non-potable }\end{array}$ & 2 & 3 & $\begin{array}{l}1 \\
0 \\
\end{array}$ & - & 2.2 \\
\hline Taiwan & $\begin{array}{c}\text { Toilet } \\
\text { flushing } \\
\end{array}$ & - & - & $\begin{array}{l}1 \\
0 \\
\end{array}$ & - & 2 \\
\hline USEPA & $\begin{array}{l}\text { Unrestricted } \\
\text { non-potable }\end{array}$ & 2 & - & $\begin{array}{l}1 \\
0 \\
\end{array}$ & 14 & - \\
\hline
\end{tabular}

Greywater characteristics are highly variable and are observed in properties such as turbidity, total suspended solids (TSS), total dissolved solids (TDS), biochemical oxygen demand (BOD), chemical oxygen demand (COD), $\mathrm{pH}$, total organic carbon (TOC), total nitrogen (TN), total phosphorous (TP) and coliforms. A more detailed analysis reveals that kitchen wastewater has the highest level of total solids (TS) and organics. Laundry sources contain the most TDS concentration among other sources, and shower wastewater involves the lowest level of TN and TP. Wastewater from baths, showers and hand basins contains soaps, shampoos, toothpaste, personal care products, skin residues, hair, hair dyes and body fats. Thus, some odor, turbidity, bacteria, anionic surfactant and high temperatures are the main characteristics of this source. In order to fulfil a water reuse guideline for the blue infrastructure of a regenerative house, a sustainable treatment unit has to be developed that satisfies the triple pillars of social, economic and environmental objectives.

A broad range of physical, chemical and biological processes have already been studied for brackish and greywater treatment. In the case of greywater treatment, critical literature review indicates that these processes individually are not sufficient to meet the required water quality standards. The major drawback for a physical process is the degradation of the organic fraction. Variation of flow and potential shock loading impacts are disadvantages of a biological process. A chemical process requires high consumption rate of chemicals which is not practical.

The present research considered a new approach to select, design and test a sustainable greywater treatment system. Multi-criteria decision analysis (MCDA) has been carried out in this research for selecting an appropriate treatment technology to meet the social, economic and environmental assessments. This procedure involves a variety of parameters which directly influence the installation and the performance of such a system. The present work suggests comparison between appropriate and innovative treatment technologies through an analytical hierarchy process (AHP). The comparison between solar powered membrane bioreactor, solar powered coagulation/disinfection and solar powered membrane distillation results the distillation method is the most sustainable for greywater treatment.

The thermally driven separation process, MD, only allow vapor to pass through a hydrophobic porous membrane. The membrane is a barrier that separates the gaseous phase from the entry liquid due to the surface tension forces which assists in the formation of a liquid-vapor boundary layer. Thus, MD is not as sensitive to feed concentration as that of RO, however, it is necessary to precisely select the physiochemical properties of the membrane in order to prevent wetting phenomenon. Membrane wetting followed by membrane fouling arises once the pressure difference across the membrane overcomes the liquid entry pressure (LEP). In such a situation, the feed solution infiltrates the membrane pores and affects the hydrophobicity nature of the membrane. The effective vapor pressure difference produced by temperature difference and/or reduced pressure across the membrane is operated in different ways in four configurations of MD such as direct contact membrane distillation (DCMD), sweeping gas membrane distillation (SGMD), vacuum membrane distillation (VMD) and air gap membrane distillation (AGMD) [4]. The VMD process has a number of advantages over conventional MD techniques. The most notable feature is that distilled water can be produced at higher flux and lower operating temperatures, resulting in lower operating costs [5].

Desalination by VMD has grown steadily over the past years. In fact, VMD is progressively becoming 
recognized and accepted as an economically, competitive and energy efficient alternative to conventional membrane separation processes such as regular distillation and RO. The VMD process rejects all non-volatile constituents such as ions, dissolved non-volatile organics, colloids and pathogenic microorganisms, and produces ultra-pure water. The vacuum pump in a VMD process reduces the permeate side pressure below the saturation pressure of the feed solution. Consequently, a liquid-vapor interface prevents contact between the liquid feed and the membrane surface. This interface minimizes the heat transfer losses within the system and reduces the potential for membrane fouling. Hence, lower energy is required to achieve similar flux in comparison to DCMD and pressure driven desalination processes [6]. Thermal energy is required to heat the feed solution in order to reach the desired temperature for the adjusted vacuum pressure. Thus, the electrical and thermal energy required for the distillation systems is supported by a solar energy.

The VMD process has been investigated by a variety of treatment tests. The lack of research regarding the quality of the permeate water regardless of feed solution for VMD was identified. Different feed solutions were treated along with exploration of the effect of a variety of operating conditions on the permeate flux. The experimental results have been compared to the theoretical models that have been introduced for the permeate flux. Wetting, one of the major drawbacks for VMD process, was intensely studied to find an appropriate solution to overcome this phenomenon. An experimental investigation of wetting problem has been carried out to investigate the influence of surfactant. The contact angle between the feed solution and the membrane surface has to be improved in order to prevent penetration of a feed solution into the membrane pores. A critical review of linear alkylbenzene sulphonate (LAS) removal in this research advises the application of coagulation for surfactant elimination resulting in contact angle enhancement. The present work designed and constructed a new solar powered VMD system with the ability to monitor online all meteorological and operating condition parameters. Extensive research in this area has been achieved via a simulation model to predict the SVMD performance.

\section{Sustainability assessment of the treatment units}

Appropriate technologies have been selected for greywater treatment considering the incorporation of solar energy and eliminating chemical consumption. The technical aspects of each treatment system is reviewed. These systems have been evaluated through analytical hierarchy process (AHP) in order to rank them on a sustainability scale. The available data of these systems are categorized into three major sustainability criteria. The mathematical analysis has been performed based on the priority of the selected criteria as well as the system score under each criterion.

\subsection{Greywater treatment units}

Greywater treatment systems could be broadly divided into physical, chemical and biological processes or a combination of them. Coarse filtration was among the first technologies investigated for greywater treatment [7]. Although the process has low-cost maintenance, it was reported that low quality effluent restricted the application of coarse filtration [8]. On the other hand, physical processes are not recommended individually for treatment of greywater due to their low efficiency in reduction of organics, nutrients and surfactants. Chemical processes such as coagulation and advanced oxidation are appropriate for turbidity and organic matter removal. High capital cost and chemical consumption are considered as disadvantages of these processes. Physicochemical processes, such as chemical coagulation followed by filtration and disinfection can produce high quality permeate which is not susceptible to chemical shocks. It was expressed that these systems are easy to scale up, but again it is not acceptable from sustainability point of view [9]. A number of biological processes showed this ability to treat greywater. Rotating biological contactor (RBC), membrane bioreactor (MBR) and biological aerated filter (BAF) were found to be suitable treatment processes since they need no chemical consumption, they are easy to scale up and they provide high quality effluent [10].

Research studies on greywater treatment using physical processes only dedicated on sand or membrane filtration and did not consider other alternative technologies. Satisfactory performance of the Nano-filtration (NF) membrane and some Ultrafiltration (UF) membranes was presented only for low strength greywater sources. However, fouling is the main drawback of these technique. Coagulation, granular activated carbon (GAC) and disinfection are known as chemical unit processes in greywater treatment area. A number of chemical technologies were tested for treatment purpose, however, higher initial costs than physical treatment units and chemical consumption are reported as the significant disadvantages. Based on the literature it is clear that the electro-coagulation (EC) followed by electrofloatation system improves the quality of reclaimed water with simple operation compare with other chemical methods [11]. This combination is considered for assessment in this research. The combination of physical and biological treatment such as MBR is highly preferred due to its small footprint, reliability and high quality of final product. A wide range of biological processes including $\mathrm{MBR}, \mathrm{RBC}$ and $\mathrm{BAF}$ have been studied for the treatment of 
greywater. The reviewed biological treatment systems show that BOD reduction was excellent in MBR and RBC systems, whereas, TSS concentration was reduced efficiently only in MBR. Hence, MBR is the next technology selected for the assessment. The biological treatment units require disinfection process to produce high quality permeate. In summary, the strength of greywater and shock loading are two major criteria that affect the biological process.

Table 2. The comparison of criteria and indicators of the proposed treatment systems

\begin{tabular}{|c|c|c|c|c|c|c|c|}
\hline \multirow{2}{*}{\multicolumn{2}{|c|}{ Indicators }} & \multicolumn{6}{|c|}{ Systems } \\
\hline & & \multicolumn{2}{|c|}{$S V M D^{b}$} & \multicolumn{2}{|c|}{ SECUFC } & \multicolumn{2}{|c|}{$S M B R^{d}$} \\
\hline \multirow{5}{*}{ 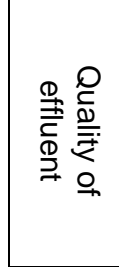 } & BOD & 0 & 100 & 10 & 94.9 & 1 & 99.3 \\
\hline & Turbidity & 0.1 & 99 & 5.23 & 95.3 & 0.2 & 99.3 \\
\hline & TSS & 2 & 99 & 10.5 & 90.3 & 1.5 & 96.1 \\
\hline & TDS & 2.1 & 99.9 & 363 & 3.46 & 782 & 19.5 \\
\hline & \begin{tabular}{|l} 
Total \\
Coli.
\end{tabular} & 0 & 7 & 800 & 4.18 & 68 & 5.9 \\
\hline \multicolumn{2}{|c|}{$\begin{array}{l}\text { Fouling and } \\
\text { cleaning }\end{array}$} & \multicolumn{2}{|r|}{$L$} & \multicolumn{2}{|c|}{$\mathrm{L}$} & \multicolumn{2}{|c|}{ M } \\
\hline \multicolumn{2}{|c|}{$\begin{array}{l}\text { Pre-treatment } \\
\text { and post- } \\
\text { treatment }\end{array}$} & \multicolumn{2}{|c|}{$\begin{array}{l}\text { Surfactan } \\
\text { removal }\end{array}$} & \multicolumn{2}{|c|}{$\begin{array}{c}\text { Screening } \\
\text { and } \\
\text { Disinfection }\end{array}$} & \multicolumn{2}{|c|}{$\begin{array}{l}\text { Screening } \\
\text { and } \\
\text { Disinfection }\end{array}$} \\
\hline \multicolumn{2}{|c|}{$\begin{array}{l}\text { Solid/brine } \\
\text { treatment }\end{array}$} & \multicolumn{2}{|r|}{ M } & \multicolumn{2}{|c|}{ M } & \multicolumn{2}{|c|}{$\mathrm{H}$} \\
\hline \multicolumn{2}{|c|}{ Capital cost ${ }^{a}$} & \multicolumn{2}{|c|}{4,235} & \multicolumn{2}{|c|}{3,740} & \multicolumn{2}{|c|}{3,610} \\
\hline \multicolumn{2}{|c|}{$\begin{array}{l}\text { Operation and } \\
\text { maintenance }\end{array}$} & \multicolumn{2}{|c|}{545} & \multicolumn{2}{|c|}{790} & \multicolumn{2}{|c|}{575} \\
\hline \multicolumn{2}{|c|}{$\begin{array}{l}\text { Electrical energy } \\
\text { consumption }\end{array}$} & \multicolumn{2}{|c|}{1.2} & \multicolumn{2}{|c|}{1.12} & \multicolumn{2}{|c|}{1.5} \\
\hline \multicolumn{2}{|c|}{$\begin{array}{l}\text { Recycled water } \\
\text { saving }\end{array}$} & \multicolumn{2}{|c|}{218} & \multicolumn{2}{|c|}{175} & \multicolumn{2}{|c|}{175} \\
\hline \multicolumn{2}{|c|}{$\begin{array}{l}\text { Public } \\
\text { acceptance }\end{array}$} & \multicolumn{2}{|r|}{ L } & $\mathrm{N}$ & & 1 & \\
\hline Simplic & & & C & $\mathrm{M}$ & & s & \\
\hline $\begin{array}{l}\text { Knowle } \\
\text { technol }\end{array}$ & $\begin{array}{l}\text { dge and } \\
\text { ogy }\end{array}$ & & $\mathrm{H}$ & L & & 1 & \\
\hline \begin{tabular}{|l|} 
Level o \\
health a
\end{tabular} & $\begin{array}{l}\text { risk to } \\
\text { ind safety }\end{array}$ & & $\mathrm{H}$ & $\mathrm{N}$ & & t & \\
\hline & & & & & & $\begin{array}{l}\text { a Sou } \\
\text { b Sou } \\
\text { c Sou } \\
\text { d Sou }\end{array}$ & $\begin{array}{l}\text { ce: }[10] \\
\text { ce: }[12] \\
\text { ce: }[13] \\
\text { ce: }[14]\end{array}$ \\
\hline
\end{tabular}

A sustainable system is nominated through a comparative study including environmental, social and technical qualitative and quantitative criteria along with economic variables. The comparative judgment of greywater treatment alternatives is performed through a process involving a relative scale of the criteria. Three solar based greywater treatment systems are evaluated in this study. The physical-basis process, SVMD, is selected as the most efficient thermally driven separation technique. The physicochemical-basis process is a solar powered electro-coagulation followed by ultrafiltration
(SECUF) technology. Lastly, the biological-basis process, a solar powered membrane bioreactor (SMBR), is a combination of a bioreactor with a membrane filtration unit, such as MF or UF.

Table 2 presents technical qualitative and quantitative data for each proposed treatment option. The quality of the permeate is considered as an environmental indicator including BOD $(\mathrm{mg} / \mathrm{L})$, turbidity (NTU), TSS (mg/L), TDS (mg/L) and total coliforms (cfu/100mL) levels. The log removal was converted to percentage, then the average of all parameters was calculated in order to align the five quality parameters. Membrane fouling and cleaning, Pre-treatment and post-treatment requirements and the sludge disposal are the other environmental indicators. Economic indicators including capital and maintenance costs as well as savings are estimated in Australian dollars per year. The energy usage is also considered and calculated in $\mathrm{kWh} / \mathrm{m}^{3}$. Social indicators are also evaluated qualitatively. The level of acceptance by people, knowledge and risk were classified into extremely high (EH), very high $(\mathrm{VH})$, high $(\mathrm{H})$, medium $(\mathrm{M})$ and low $(\mathrm{L})$. The simplicity is also a social indicator. The classification for complexity is: very complex (VC), moderately complex (MC), complex (C), simple (S) and very simple (VS).

\subsection{Decision analysis}

A systematic and analytic model solves such a complicated problems and nominate the best alternative for decision makers. The MCDA technique identifies the most sustainable technology option. AHP, one of the most widely applied pairwise comparison method among the few MCDA methods, establishes a weighting system for alternatives. AHP is optimized Precisely to evaluate the treatment systems against the three sustainability pillars. Twelve indicators under the three major criteria have been incorporated in AHP judgement. Decision makers considered economic and environmental aspects of treatment unit more important than social criteria for the comparative judgment. Hence, a ratio of 2 and 4 are selected for economic versus environmental and economic versus social, respectively. This ratio presents the importance of economic criterion compare with environmental and social criterion. On the other hand, a ratio of 3 is considered for environmental versus social criterion. The same pair-wise comparison was performed for indicators, separately. The three systems were also assessed through all indicators. Weighting was performed simply for both qualitative and quantitative indicators. The numeralised method converted qualitative criteria in a same comparison range of quantitative ones. It has to be noted that technical data for different treatment units are derived from available reviewed articles. Finally, the three treatment 
alternatives were assessed through the defined criteria and indicators and the most sustainable option was nominated. The proposed treatment systems SVMD, SECUF and SMBR are ranked by the score of 0.40 , 0.26 and 0.34 , respectively. Consequently, the SVMD system is considered as the most sustainable treatment system for greywater application. The diverse nature of the proposed systems was verified through sensitive analysis of the comparative judgement. Various combinations of economic, social and environmental ratios were applied in this analysis. SVMD was the first rank in the majority of possible priority rankings of the major criteria due to its high quality effluent and reasonable maintenance costs

\section{Materials and methods}

Synthetic greywater has been formulated through the suggested greywater technology testing protocol [15]. The typical parameters of the synthetic greywater were also determined and compared to the available water quality parameters in order to evaluate the given recipe. Natural greywater was also prepared from a house. The collected sample comprised of wastewater from the kitchen $11 \%$, laundry $36 \%$, shower $41 \%$ and basin $12 \%$. Greywater samples treated by VMD. MD02CP2N membrane module supplied by MICRODYN in hollow fiber form contains 40 capillaries. It is a propylene (PP) membrane with $0.2 \mu \mathrm{m}$ pore size and $0.1 \mathrm{~m}^{2}$ area. It was found that membrane wetting, limits the selection of membrane for MD. Flat sheet samples of the three types of hydrophobic membranes were tested through contact angle measurements. Contact angle was determined using the average angle between the left and right end points between a liquid droplet on a sheet of membrane. It was calculated via 200-F1 Goniometer (Ramè-Hart) using a camera and computer software. The accuracy of the instrument is \pm 0.1 degree.

The assessment of the VMD performance requires water quality measurements. Water quality parameters of prepared samples were measured prior to and after each test. The analytical parameters were measured in regard to the standard methods for water and wastewater. These include temperature, $\mathrm{pH}$, TSS, TDS, turbidity, ion concentration, COD, TOC, TN, TP and E.coli.

A N820 Javac KNF laboratory vacuum pump used to operate $-99.2 \mathrm{kPa}$ ultimate gauge pressure by a flow rate of $20 \mathrm{~L} / \mathrm{min}$. A coil condenser contains three cavities of glassware used for permeate vapor. The cold stream inside the middle tube condenses vapor inside the inner cavity. The spiral-wound inner cavity is connected to the third (outer) cavity which is placed to collect the condensed vapor. The diameter of the coil is $10 \mathrm{~mm}$ and it is surrounded in a $300 \mathrm{~mm}$ glassware column.
The VMD was connected to solar PV panels, a solar collector and an EC unit for greywater treatment as a stand-alone system. Two SunPower SPR-210 PV panels were used in this study to supply ultimate 420 $\mathrm{W}$ power at $48 \mathrm{VDC}$ with a total area of $2.48 \mathrm{~m}^{2}$. A solar regulator charges two deep cycle batteries $(24 \mathrm{~V}$ each) connected in series, and provides energy requirement for the pumps and the EC unit. A Lorentz ETRACK controller was also assisted in tracking the sun to increase the efficiency of the system. The solarthermal collector was attached to the PV panels for the same reason of sun tracking. The collector transfers heat energy from the solar source into the feed solution by conduction. The collector with the area of $1.5 \mathrm{~m}^{2}$ and capacity of $6 \mathrm{~L}$ is benefitted by insulation for the entrance and exit hoses. The PV panels, the collector and the Solar Electro-coagulation and Vacuum Membrane Distillation (SECVMD) arrangement are shown in Figure 1.
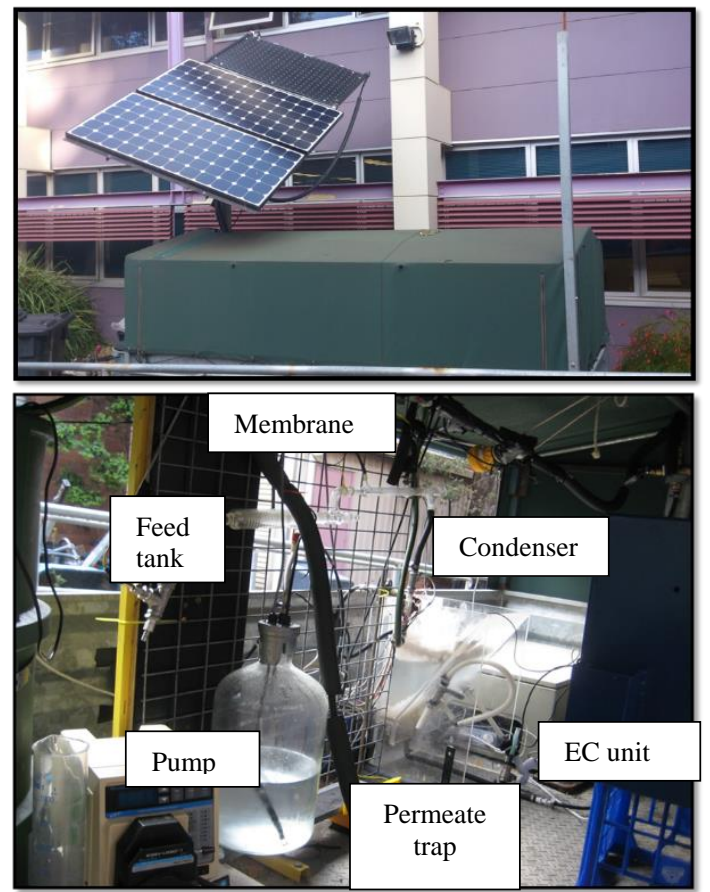

Figure 1. Solar PV panels, collector and the SECVMD set-up

\section{Experimental evaluation of the solar powered vacuum membrane distillation system}

An improved VMD process coupled with solar energy is shown in Figure 2. Electricity for the pumps is provided by two PV panels. The thermal collector heat feed water before it enters the membrane module. The solar collector consists of $1.5 \mathrm{~m}^{2}$ area along with insulation for the entrance and exit hoses. SVMD consists of two separate loops and a distillate channel. The feed solution which is distilled water is passed 
through the first loop from the condenser inlet to a storage container which is designed to increase the temperature for energy savings. Feed water is passed through the condenser to condense the permeate vapor while feed water temperature rises. The feed water is then heated in the second loop by the solar collector and directed along to the membrane module. Permeate water is collected in the permeate trap after condensation. The MD02CP2N membrane module creates an interface between the feed solution and the vapor on the permeate side.

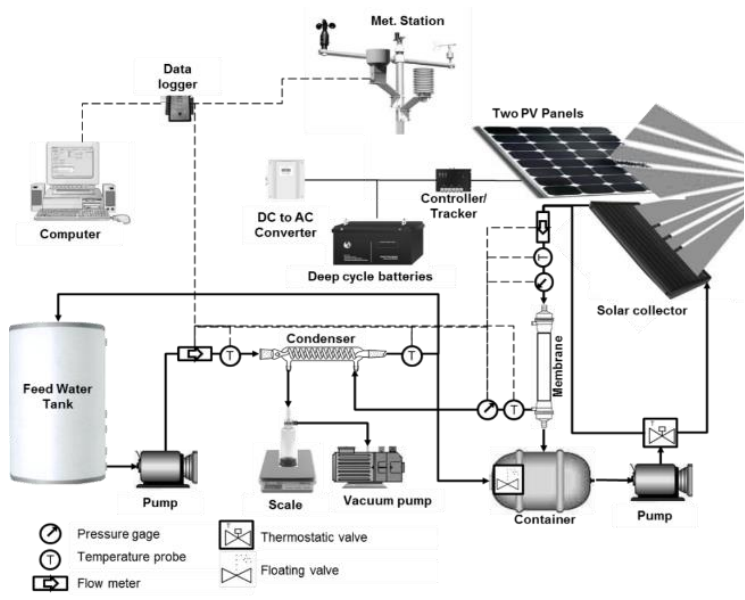

Figure 2. Solar powered vacuum membrane distillation system

A variety of transducers and sensors were embedded to monitor the weather conditions, system performance and water quality. Temperature probes were located across the condenser, thermal collector outlet and at the membrane inlet. The vapor temperature is monitored by temperature sensor on the permeate side of the membrane. The flow-meters measured the flow rate of cold and hot feed streams. The vacuum pressure on the permeate side of the membrane was monitored by the pressure probe. The weight of the permeate water was monitored by a BA4100 Sartorius balance $( \pm 0.1 \mathrm{~g})$. These data were transferred to the data logger as well as the climate parameters such as temperature, humidity, solar irradiance, wind speed and direction.

Distilled water circulated through the SVMD system to evaluate the performance. The graphs in Figure 3 represent the typical daily measurements of experimental flux, solar irradiance, electrical conductivity of the permeate for specific dates. Solar irradiance increases feed-water temperature using the thermal collector and directly influences the rate of flux, since the vacuum pressure is constant. The gradually variation of the solar irradiance is observed and results in steadily increase and decrease of the flux rate. Solar irradiance rises feed-water temperature via the thermal collector and directly influences the rate of flux. The feed water temperature is also directly affected by the ambient temperature.
The maximum distillate production was registered at maximum irradiance and ambient temperature. Certainly, the morning and afternoon irradiance were not sufficient to increase the water temperature to the required level. The system was located in a relatively shaded area where availability of direct solar input was limited. Experimental results demonstrates that there is a remarkable improvement in distillate production rate at high ambient temperatures where the solar irradiance is similarly trends. For all performed tests, electro-conductivity varied between 0.6 to $1.6 \mu \mathrm{S} / \mathrm{cm}$ that shows a high quality of the permeate water.

Desalination of two saline solutions 5 and $20 \mathrm{~g} / \mathrm{L}$ $\mathrm{NaCl}$ were tested using SVMD. A three-day test was carried out. There is no considerable effect of feedwater salinity concentration of $5 \mathrm{~g} / \mathrm{L}$ on the permeate flux. However, the salinity concentration of $20 \mathrm{~g} / \mathrm{L}$ impacted on the decline rate of the permeate flux during the second day. The experimental flux rates for was reduced by $38 \%$ during the second day of the experiment. Higher salinity concentration decreases the permeate flux rate. This is correspondent to the open pore area reduction. Salt removal efficiency was above $99.9 \%$. This clearly shows that there is no dissolved sodium chloride in the permeate trap. There was also no observation of pore wetting problem in this system.
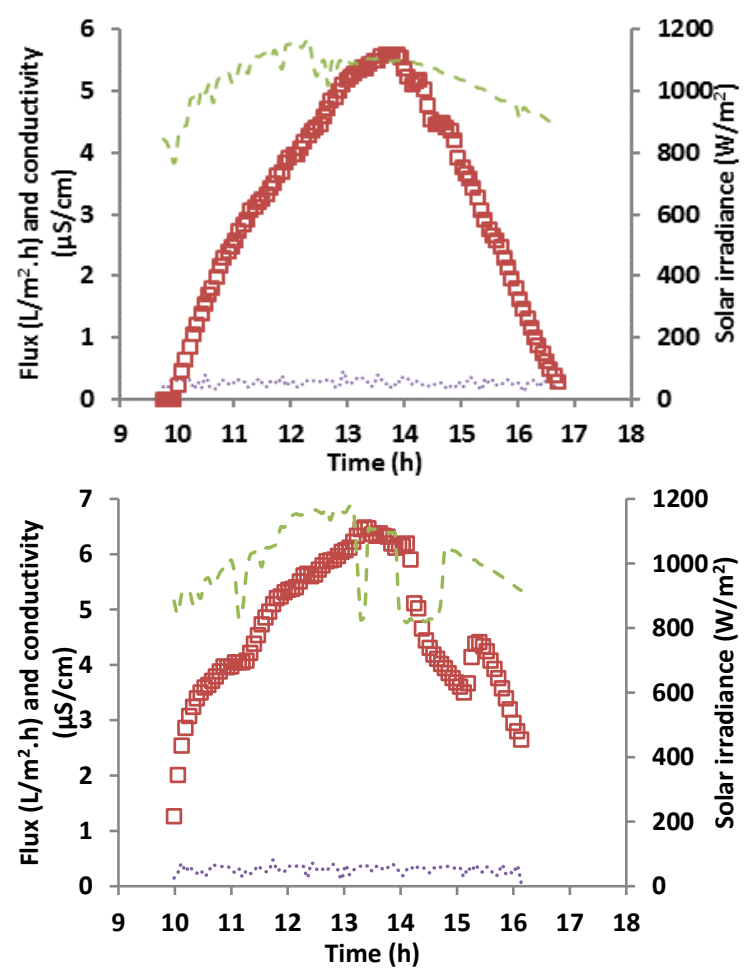


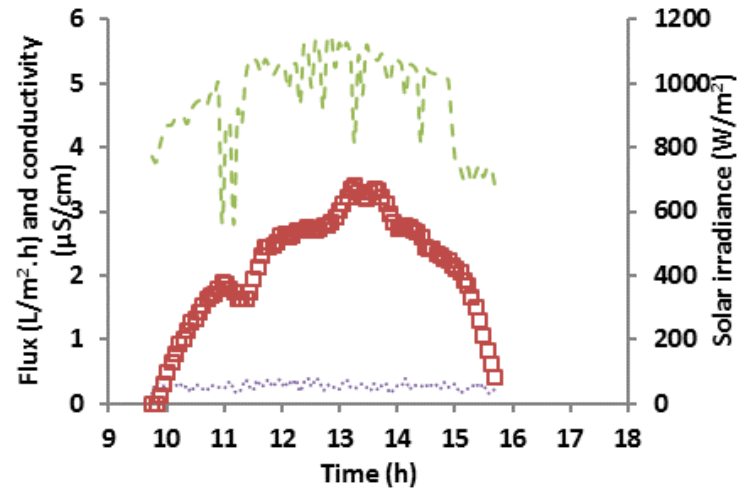

Figure 3. The experimental rate of flux $(\square)$, solar irradiance $(-)$ and electrical conductivity of the permeate $(\cdots)$ for the SVMD test during a day

\section{Wetting phenomenon}

Feed water passes directly through the membrane without phase changes if the hydrostatic pressure across the membrane feed side to the permeate side exceeds the LEP of the membrane. The VMD process has not been employed in greywater reclamation since active surfactant in detergents promote wetting of the membrane [16]. Parameters such as membrane material, porosity, pore size, thermal conductivity, pore size distribution, surface tension of the solution, LEP and contact angle should be carefully considered to prevent pore wetting [17]. The contact angle between the feed solution and the membrane surface is a dominant parameter that has to be determined before any VMD test. This helps to investigate membrane cleaning intervals in order to avoid the critical point of wetting.

Linear alkylbenzene sulfonic acid $(97 \%$ w/w Alfa Aesar) diluted into distilled water at desired concentration levels to prepare LAS standard solutions. The absorbance of prepared samples was measured at a wavelength of $652 \mathrm{~nm}$ by a spectrophotometer to provide the calibration curves. The absorbance of the greywater samples was substituted in the calibration curve equation to determine the concentration of LAS. The final concentrations for each greywater sample are shown in Table 3.

Table 3. The LAS concentration and contact angle for each greywater sample

\begin{tabular}{|c|c|c|c|}
\hline $\begin{array}{c}\text { Greywate } \\
\text { r Sample }\end{array}$ & $\begin{array}{c}\text { Absorbanc } \\
\text { e at } 652 \\
\mathrm{~nm}\end{array}$ & $\begin{array}{c}\text { LAS } \\
\text { concentration } \\
(\mathrm{mg} / \mathrm{L})\end{array}$ & $\begin{array}{c}\text { Contac } \\
\text { t angle }\end{array}$ \\
\hline Laundry & 3.215 & 12.75 & 88.01 \\
\hline Shower & 3.311 & 13.14 & 87.99 \\
\hline Kitchen & 3.913 & 15.56 & 87.85 \\
\hline Mixed & 3.412 & 13.55 & 87.96 \\
\hline Synthetic & 3.651 & 14.51 & 87.90 \\
\hline
\end{tabular}

Contact angles were measured using the goniometer for greywater samples on the PP membrane surface. Contact angles below $90^{\circ}$ depicted wetting phenomenon occurrence. The average contact angle of $87.94^{\circ}$ for greywater samples reflects the statement on the effect of LAS on pore wetting. The contact angle measurement is pictured in Figure 4. The $87.9^{\circ}$ angle is accordance with absorbance unit of 3.651 which is attributed to the LAS concentration of $17.13 \mathrm{mg} / \mathrm{L}$. To avoid the wetting phenomenon (for this type of membrane), the LAS concentration has to be reduced to $4 \mathrm{mg} / \mathrm{L}$.

\section{Synthetic grey water/PP $\theta=87.9$}

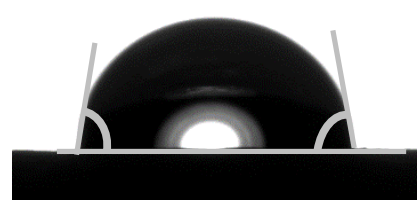

Figure 4. The contact angle measurement for a synthetic greywater droplet on a PP membrane surface

\section{Electro-coagulation, a suitable pretreatment unit}

The main impediments of VMD for greywater treatment is the wetting phenomenon. Thus, a suitable pre-treatment unit is necessary to reduce LAS concentration results in successful treatment by VMD system. UF was introduced as an effective process for surfactant removal, though, high concentration of surfactant results in the reduction of the permeate flux and critical micelles concentrations [18]. Laundry wastewater was treated by a bipolar electrocoagulation/electro-flotation process [19]. Acceptable removal of turbidity, COD, TP and surfactants in a wide $\mathrm{pH}$ range (5-9) at a short hydraulic retention time (HRT) of 5 to 10 minutes. was achieved. The 2.8 L EC reactor comprises of eight pieces of Ti plates and 21 pieces of Al plates. This application removed 80\% COD concentration, 95\% LAS concentration and 99.9\% turbidity. EC is more preferred than a chemical type of coagulation unit from a sustainability point of view. The flexible operation and avoiding the use of chemicals lends it to the use of PV panels to provide its power.

During coagulation and flotation, surfactants are rejected by means of either the reaction between charged ionic species with ion of the opposite charge, or with a flocculation by means of metallic hydroxides. In case of using Aluminum plates, coagulation is performed by aluminum hydroxides due to adsorption of the particles to neutralize the colloidal charges. Then floatation takes place when hydrogen bubbles are produced at the cathode, and 
adhere to the flocculated species. A sedimentation tank is required to settle the dense flocculated species. Electrolysis time, current density, rate of agitation, number and distance between electrodes, retention time, type of power supply, type and shape of electrode and $\mathrm{pH}$ are the operating parameters that has influence on EC.

Various operating times and densities were tested for the independent $\mathrm{EC}$ unit to determine the appropriate operating configuration. Five parallel Aluminum plates with total active area of $0.16 \mathrm{~m}^{2}$ were placed in the EC unit. The first reactor is connected to the sedimentation chamber with a weir to allow the coagulated water to spill over. Five different current densities $(12.5,25,37.5,50,62.5$ $\left.\mathrm{A} / \mathrm{m}^{2}\right)$ and five different circulation rates $(0.25,0.50$, $0.75,1.00,1.25 \mathrm{~L} / \mathrm{min}$ ) were tested. Parameters such as $\mathrm{pH}$ and electrical conductivity were monitored online. The contact angle with a PP membrane was measured at 2, 4, 6, 8, 10, 30 and 60 minutes' intervals of operation time. Turbidity, TP, TN, TOC, COD and Faecal coliforms were also measured for the permeate sample at the end of each test.

Higher contact angle as well as more water quality improvement is achieved with higher current density and higher circulation rate of EC unit. Figure 5 describes that the contact angle increased sharply for the first 5 to 10 minutes of operation, so a minimum operation time is enough to achieve a contact angle above $100^{\circ}$. The circulation rate of $0.75 \mathrm{~L} / \mathrm{min}$ significantly increased the contact angle from an average $78^{\circ}$ to $100^{\circ}$ at $44,14,8,5$ and 5 minutes for $12.5 \mathrm{~A} / \mathrm{m}^{2}, 25 \mathrm{~A} / \mathrm{m}^{2}, 37.5 \mathrm{~A} / \mathrm{m}^{2}, 50 \mathrm{~A} / \mathrm{m}^{2}$ and 62.5 $\mathrm{A} / \mathrm{m}^{2}$, respectively as shown in Figure 5 .

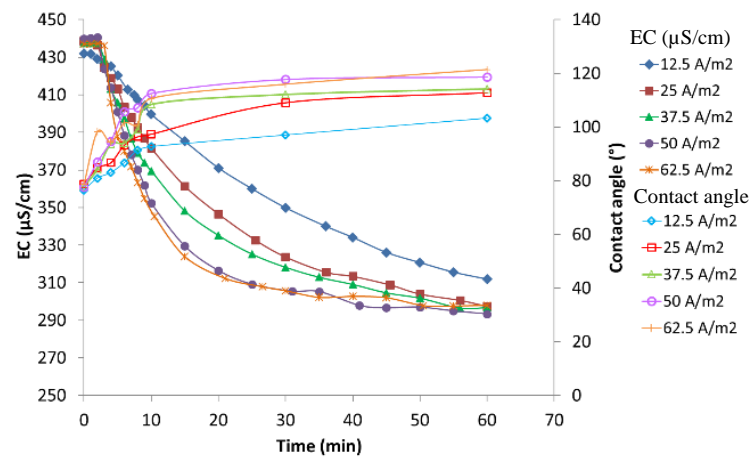

Figure 5. Electrical conductivity (primary axis) and contact angle measurements (secondary axis) versus operation time for $0.75 \mathrm{~L} / \mathrm{min}$ circulation rate at various current densities $\left(\mathrm{A} / \mathrm{m}^{2}\right)$

The EC process removed $94.4 \%$ of turbidity from an initial turbidity value of 25.5 NTU. TOC concentration was reduced by $71.0 \%$ from $54.5 \mathrm{mg} / \mathrm{L}$ for raw greywater. Greywater COD concentration also decreased from $404.5 \mathrm{mg} / \mathrm{L}$ to $65.5 \mathrm{mg} / \mathrm{L}$. The $83.8 \%$ removal rate illustrates the elimination of organic matter from the solution. TN and TP concentrations reduced by an average $73.1 \%$ and
$96.1 \%$, respectively. The main reaction is between phosphate and nitrate with aluminium. The EC process also showed a low 1.32 log removal of faecal coliforms.

\section{Solar vacuum membrane distillation preceded by electro-coagulation pretreatment}

The power required for the EC unit is the total power used by the circulation pump and the DC power supply. The energy consumption for each test is determined as the total power multiplied by operating time required to achieve a contact angle above $100^{\circ}$. Therefore, energy consumption and contact angle are the main parameters to evaluate the optimum operating condition. The calculation was performed for the results of two tests at $25 \mathrm{~A} / \mathrm{m}^{2}$ and $37.5 \mathrm{~A} / \mathrm{m}^{2}$ current densities. This decision has been made since the most effective increase rate of the contact angle was observed for them. The lowest energy consumption is $9.12 \mathrm{Wh}$ which occurs at the peak point correspondence to current density of $43.5 \mathrm{~A} / \mathrm{m}^{2}$. The EC unit is able to remove surfactants and achieve 100 contact angle within $5 \mathrm{~min}$ at a circulation rate of $0.75 \mathrm{~L} / \mathrm{min}$ and current density of $43.5 \mathrm{~A} / \mathrm{m}^{2}$.

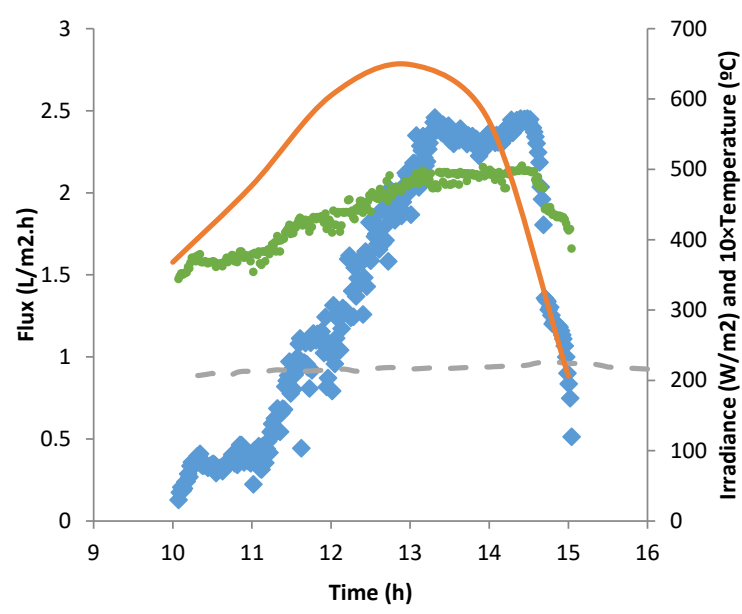

Figure 6. The permeate flux ( $\diamond)$ for SECVMD, solar irradiance (-) and ambient temperature (--) and feed water temperature $(\bullet)$ during a day

The sustainable water treatment system presented in Figure 1 treated greywater for five hours. The hot stream flow rate was adjusted manually for 0.75 $\mathrm{L} / \mathrm{min}$, and, experiments were carried out under high vacuum pressure at $6 \mathrm{kPa}$. The maximum flux rates about $2.4 \mathrm{~L} / \mathrm{m}^{2}$.h were achieved between $13: 15$ to 14:15 hours due to the highest solar radiation at 13:00 as shown in Figure 6. There are clear differences between the distribution of the permeate flux results from 10:00 am to $3: 00 \mathrm{pm}$. This is due to the temperature rise of the feed solution progressing mass 
and heat transfer mechanisms. Feed-water temperature is the main governing variable that controls the distillate production rate, since the flow rate and vacuum pressure were kept constant. From 11:00 to 13:00 the feed solution temperature increased marginally from 38 to $49{ }^{\circ} \mathrm{C}$, respectively. Solar irradiance trend clarifies this feature. There is less effect by the ambient temperature in the variation of the feed water temperature, since this parameter was relatively constant at $21^{\circ} \mathrm{C}$. Maximum distillate flux varied from 2.1 to $6.5 \mathrm{~L} / \mathrm{m}^{2} \mathrm{~h}$ during the two-month tests. The variation of the permeate flux was the result of changes in feed-water temperature which was correspondent to solar irradiance, ambient temperature and wind speed.

\section{Conclusion}

The study was set out to experimentally investigate the performance of a world first innovative solar powered treatment system for greywater reuse. The existing greywater treatment technologies were studied. The most sustainable treatment system was determined through a systematic and mathematical decision analysis method. Laboratory and field studies were carried out, and the problems encountered for greywater treatment were solved by means of an appropriate pre-treatment EC unit. Three sustainable treatment systems adapted with solar energy were introduced. The AHP technique evaluated the proposed systems based on the information chosen for economic, environmental and social indicators. Pairwise comparative judgement led to determine the weight of each indicator and weight of each alternative associated with every indicator. Accordingly, the SVMD system was selected as the most sustainable solution for treatment.

A pilot scale solar powered VMD system was designed, built and examined to analyse its performance under real weather conditions. Experiments in the SVMD system were carried out for a two month period and the results showed that the rate of permeate flux is seriously influenced by the solar irradiance, since pressure and flow rate were maintained at $6 \mathrm{kPa}$ and $0.75 \mathrm{~L} / \mathrm{min}$, respectively. As expected maximum distillate flux was achieved between 12 to $2 \mathrm{pm}$ when high solar irradiance occurred, and the permeate flux varied from 2.1 to 6.5 $\mathrm{L} / \mathrm{m}^{2} \mathrm{~h}$ depending on the dynamic weather conditions. Experimental study was accomplished for fresh water and saline solutions. The SVMD system was able to reject dissolved matters from the solutions, since the electrical conductivity values of the permeate water were in the range of $0.6-1.6 \mu \mathrm{S} / \mathrm{cm}$. It was also concluded that salinity concentration below $5 \mathrm{~g} / \mathrm{L}$ had an intangible effect on the permeate flux rate, however, up to $38 \%$ flux decline was observed for 20 $\mathrm{g} / \mathrm{L}$.
Scaling also may cause a pore wetting problem which can discontinue the distillation function. Low contact angle between the solution and the membrane surface is another reason for pore wetting. Experimental works carried out for pore wetting phenomenon illustrated that contact angle is associated with the concentration of LAS in the solution. The contact angle measured for variety of LAS concentration solutions showed that higher LAS concentration reduces the contact angle that may result in pore wetting if the value reached below the $90^{\circ}$.

To surmount the pore wetting problem which was the barrier for grey water treatment using SVMD, a pre-treatment unit was incorporated. Greywater was successfully treated by a stand-alone SECVMD system. Pure water extraction on the permeate side of the membrane demonstrated the successful avoidance of wetting phenomenon. The EC unit was able to remove LAS from greywater by only 5 minutes of electrocoagulation/floatation at $37.5 \mathrm{~A} / \mathrm{m}^{2}$ and 0.75 $\mathrm{L} / \mathrm{min}$ circulation rate. The EC unit not only performed well as a pre-treatment process but also it has improved the quality of feed water. TSS, TP and turbidity levels were reduced by more than $90 \%$ by means of EC. This results a higher permeate flux rate and higher membrane life time. This technology is able to reuse greywater generated at a typical household. The decentralized SECVMD system produces pure water from greywater and is capable of saving up to $70 \%$ water at each regenerative house.

\section{References}

[1] Elmitwalli, T.A., Shalabi, M., Wendland, C. and Otterpohl, R. (2007), 'Grey water treatment in UASB reactor at ambient temperature'. 12 Caxton Street, London, SW1H 0QS, United Kingdom: IWA Publishing.

[2] Al-Jayyousi, O.R. (2003), 'Greywater reuse: towards sustainable water management', Desalination. 156(1-3), pp. 181-192.

[3] Sivakumar, M. and Ramezanianpour, M. (2012), 'Green technology options for greywater treatment'. in National Convention of Environmental Engineers Mangalore local centre, Karnataka, India.

[4] Khayet, M. (2011), 'Membranes and theoretical modeling of membrane distillation: A review', Advances in Colloid and Interface Science. 164(1-2), pp. 56-88.

[5] Safavi, M. and Mohammadi, T. (2009), 'High-salinity water desalination using VMD', Chemical Engineering Journal. 149(1-3), pp. 191-195.

[6] Mericq, J.-P., Laborie, S. and Cabassud, C. (2011), 'Evaluation of systems coupling vacuum membrane distillation and solar energy for seawater desalination', Chemical Engineering Journal. 166(2), pp. 596-606. 
[7] Hypes, W., Batten, C.E. and Wilkins, J.R. (1975), 'Processing of combined domestic bath and laundry waste waters for reuse as commode flushing water.', Report NASA TN D-7937.

[8] Li, F., Wichmann, K. and Otterpohl, R. (2009), 'Review of the technological approaches for grey water treatment and reuses', Science of The Total Environment. 407(11), pp. 3439-3449.

[9] Sostar-Turk, S., Petrinic, I. and Simonic, M. (2005), 'Laundry wastewater treatment using coagulation and membrane filtration', Resources, Conservation and Recycling. 44(2), pp. 185-196.

[10] Friedler, E. and Hadari, M. (2006), 'Economic feasibility of on-site greywater reuse in multi-storey buildings', Desalination. 190(1-3), pp. 221-234.

[11] Wang, C.-T., Chou, W.-L. and Kuo, Y.-M. (2009), 'Removal of COD from laundry wastewater by electrocoagulation/electroflotation', Journal of Hazardous Materials. 164(1), pp. 81-86.

[12] Sivakumar, M., Ramezanianpour, M. and O'Halloran, G. (2013), 'Brackish Water Treatment for Reuse Using Vacuum Membrane Distillation Process', in 9th IWA International Conference on Water Reuse. IWA: Windhoek, Namibia. pp. 1-8.

[13] Bani-Melhem, K. and Smith, E. (2012), 'Grey water treatment by a continuous process of an electrocoagulation unit and a submerged membrane bioreactor system', Chemical Engineering Journal. 198-199(0), pp. 201-210.

[14] Merz, C., Scheumann, R., El Hamouri, B. and Kraume, M. (2007), 'Membrane bioreactor technology for the treatment of greywater from a sports and leisure club', Desalination. 215(1-3), pp. 37-43.

[15] Diaper, C. (2001), 'Small scale water recycling systems-risk assessment', Water Science and Technology. 10, pp. 83-90.

[16] Gryta, M. (2008), 'Fouling in direct contact membrane distillation process', Journal of Membrane Science. 325(1), pp. 383-394.

[17] Li, N.N., Matsuura, T., Ho, W.S.W. and Fane, A.G. (2008), 'Advanced Membrane Technology and Applications'. Wiley: Hoboken.

[18] Kowalska, I. (2008), 'Surfactant removal from water solutions by means of ultrafiltration and ion-exchange', Desalination. 221(1-3), pp. 351-357.

[19] Ge, J., Qu, J., Lei, P. and Liu, H. (2004), 'New bipolar electrocoagulation-electroflotation process for the treatment of laundry wastewater', Separation and Purification Technology. 36(1), pp. 33-39. 